\title{
Simple analysis of soil structure effects based on geothermal exploitation
}

\author{
Yan.Ge ${ }^{1, a^{*}}$, Zhenzhen. Wang ${ }^{2}$, Xuan.Huang ${ }^{1}$, Wei.Lu ${ }^{1}$, Xiaohe. Ji², Can.Zhang ${ }^{2}$ \\ ${ }^{1}$ No.2. Institute of Geo-Environment Survey of Henan, Zhengzhou,450053, China \\ ${ }^{2}$ Bureau of Ecology and Environment of Pu Yang City, 457000, China
}

\begin{abstract}
You should leave $8 \mathrm{~mm}$ of space above the abstract and $10 \mathrm{~mm}$ after the abstract. The heading Abstract should be typed in bold 8,5-point Times. The body of the abstract should be typed in normal 8,5point Times in a single paragraph, immediately following the heading. The text should be set to 1.15 line spacing. The abstract should be centred across the page, indented $15 \mathrm{~mm}$ from the left and right page margins and justified. It should not normally exceed 200 words. 1 Introduction
\end{abstract}

\section{Introduction}

With the deepening of people's understanding of new energy, geothermal has become more and more "hot." Henan's abundant geothermal resources will be an important resource pillar for the future economic growth of the Central Plains. Its development and utilization will be one of the important measures for energy conservation and emission reduction, optimization of energy structure, reduction of air pollution and improvement of people's living standards. However, with the development and utilization of geothermal resources, the soil structure will be affected to a large extent[1][2].

The development of shallow geothermal energy in Henan Province is mainly realized by heat pump units, which are divided into two methods:geothermal heat pump groundwater heat exchange system and ground source heat pump buried pipe heat exchange system. The vertical buried pipe heat exchange system can obtain lowgrade heat energy from the soil in the formation.Vertical buried pipes are generally installed between 50-120 meters underground.The underground U-shaped PE pipe is connected with the ground heat pump unit. The fluid medium or antifreeze in the closed PE plastic pipe transfers the underground heat energy to the heat pump, and then the heat pump unit raises the low-grade heat energy to the building. It is suitable for heating and cooling of larger buildings.Zhengzhou A area is located in the alluvial plain of Yellow River. The stratum is mainly silt and silt sand, suitable for shallow geothermal vertical buried pipe heat exchange system. Heating and cooling area reaches $100,000 \mathrm{~m}^{2}$.

This analysis is to analyze the influence of the operating temperature of heat pump unit on soil structure. The soil samples are taken from the different positions of heat pump unit operation to determine the total number of microorganisms, soil potassium, organic carbon and total phosphorus in the soil at different temperatures. Changes in potassium content [3][4].

\section{Test content and method}

This experiment used control variable method and single factor experiment.

After collecting soil samples, the physical and chemical properties of the original soil such as the total number of microorganisms, organic carbon content, total nitrogen content, total phosphorus, and potassium content were determined.

Simulate soil temperature change: place the collected soil stored in the sealed bag in a constant temperature water bath, change the temperature of the constant temperature water bath, simulate the temperature gradient to $30^{\circ} \mathrm{C}, 40^{\circ} \mathrm{C}, 50^{\circ} \mathrm{C}, 90^{\circ} \mathrm{C}$, soil samples in each Keep it for 4 days in temperature.

The total number of microorganisms, organic carbon, total nitrogen, total phosphorus and potassium at different temperatures were determined. details as follows:

\subsection{Total number of microorganisms}

10 gram of the collected soil was weighed into $90 \mathrm{ml}$ of sterile water, shaken and allowed to stand for 20 minutes; inoculated with beef paste-peptone medium on a clean bench; cultured in a $37^{\circ} \mathrm{C}$ incubator for 48 hours; total bacterial community statistics were performed.

\subsection{Determination of organic carbon}

Adopting "HJ 615-2011 Determination of Soil Organic Carbon - Potassium Dichromate Oxidation Spectrophotometric Method"Weigh 0.4gram of soil sample in a $50 \mathrm{ml}$ plug colorimetric tube; add $0.1 \mathrm{~g}$ mercury sulfate and $5.00 \mathrm{ml}$ potassium dichromate 
solution, shake separately; then slowly add $7.5 \mathrm{ml}$ concentrated sulfuric acid and gently shake it; After the colorimetric tube is wrapped, it is placed in a highpressure steam sterilization pot, digested for $45 \mathrm{~min}$ at $134^{\circ}$ $\mathrm{C}$, and cooled; the volume is adjusted to $50 \mathrm{ml}$ with water, and allowed to stand for 8 hours; the absorbance is measured at $585 \mathrm{~nm}$; Also do a blank experiment.

\subsection{Determination of total phosphorus in soil}

Adopting "HJ 632-2011 Determination of Total Phosphorus in Soils - Alkali Fusion - Molybdenum Antimony Anti-Spectrophotometry" weigh 0.2500 gram soil sample in the crucible; wet the soil sample with a few drops of absolute ethanol; add 2 gram sodium hydroxide solid to the surface of the sample, cover the sample, cover the lid; put the crucible into the muffle furnace. When the temperature rising to about $400^{\circ} \mathrm{C}$, hold for $15 \mathrm{~min}$.

Then continue to raise the temperature to $640{ }^{\circ} \mathrm{C}$, holdingfor $15 \mathrm{~min}$ and take out it and cool. Then add 10 $\mathrm{ml}$ of ammonia-free water to the crucible to heat to $80^{\circ} \mathrm{C}$. After melting, Transfer all the solution to a $50 \mathrm{ml}$ centrifuge tube and wash it with $10 \mathrm{ml}$ of $3 \mathrm{~mol} / 1$ sulfuric acid solution three times. Then rinse with distilled water and transfer all the washing solution to the centrifuge tube.Then centrifuge at $2500 \mathrm{r} / \mathrm{min}$ for $10 \mathrm{~min}$ and let stand transfering the supernatant Dilute to $100 \mathrm{ml}$ volumetric flask. Pipet $10 \mathrm{ml}$ soil suspension into $50 \mathrm{ml}$ plug colorimetric tube and dilute to the mark with water adjusting $\mathrm{pH}$ to 4.4 . Next add $1 \mathrm{ml}$ ascorbic acid solution and shake.Then add $2 \mathrm{ml}$ molybdic acid. The salt solution was shaken well.After standing for $15 \mathrm{~min}$, the absorbance was measured at a wavelength of $700 \mathrm{~nm}$, and a blank experiment was performed.

\section{Test results}

\section{1 sampling point position}

The sampling point locations are shown in table 1 and figure 1.

Table 1. Zhengzhou A area samplingpoint layout table.

\begin{tabular}{|c|c|c|}
\hline Position & Temperature & Abbreviation \\
\hline $\begin{array}{c}\text { No. } 1 \text { hole } \\
\text { Surface }\end{array}$ & $32.8^{\circ} \mathrm{C}$ & No.1 \\
\hline $\begin{array}{c}\text { No. } 1 \text { hole } \\
20 \mathrm{~cm}\end{array}$ & $28.6^{\circ} \mathrm{C}$ & No.2 \\
\hline $\begin{array}{c}\text { No. } 2 \text { hole } \\
\text { Surface }\end{array}$ & $26.4^{\circ} \mathrm{C}$ & No.3 \\
\hline $\begin{array}{c}\text { No. } 2 \text { hole } \\
20 \mathrm{~cm}\end{array}$ & $26.0^{\circ} \mathrm{C}$ & No.4 \\
\hline
\end{tabular}

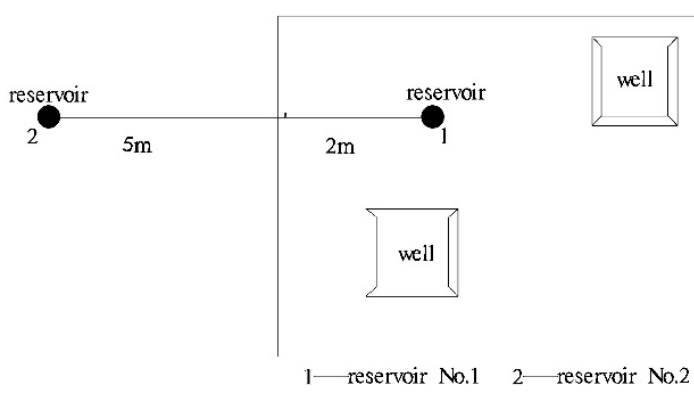

Fig1. Reservoir sampling point plane position map in Zhengzhou A area.

\section{2 test results}

\subsubsection{Microbiological test results}

The effects of reservoir temperature on microorganisms in Zhengzhou District A are shown in Figure 2 and Figure 3.

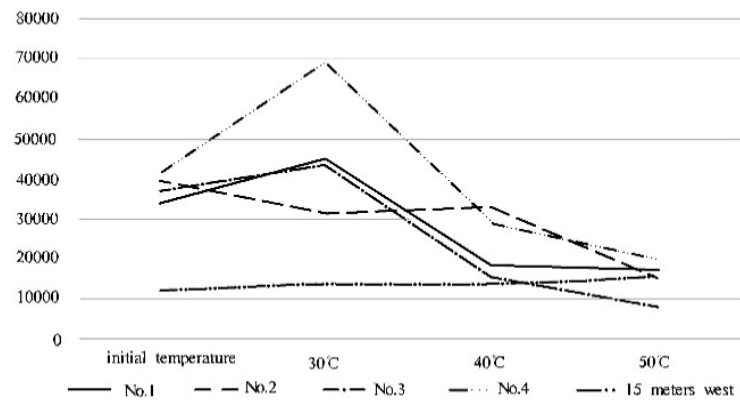

Fig2. Total number of microorganisms changing treng with temperature.

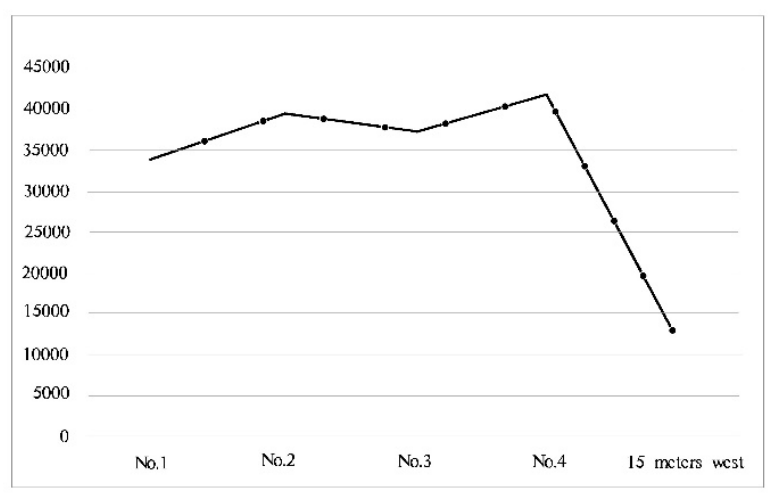

Fig3. Total number of microorganisms changing treng with distance.

Table 1, Figure 1, Figure 2 and Figure 3 show that:

(1) When the initial temperature being less than $30^{\circ} \mathrm{C}$, the number of microorganisms increases rapidly with the increase of temperature.

(2) When the temperature reaching $40^{\circ} \mathrm{C}$, the number of microorganisms reaches the highest value. With the increasing of temperature, the number of microorganisms grows slowly or decreases.

(3) The closer to the reservoir or the water well, the more obvious the change of microorganisms is.

(4) When the initial temperature exceeding $30{ }^{\circ} \mathrm{C}$, the change of microorganisms with temperature is slightly 
lower than that of the reservoir, and it changes slowly when it being far away from the reservoir.

This shows that: the continuous development of geothermal resources has a certain impact on soil microbes. The microorganisms in the soil are mainly bacteria. Among them, the amount of bacteria in the soil accounts for $70 \%$ to $90 \%$ of the total amount of microorganisms in the soil, and there are many kinds of bacteria, mainly heterotrophic bacteria, and a small amount of autotrophic bacteria [5].

The various types of fungi that are present in the surface soil are mostly semi-infected. The presence of many microorganisms in the soil has a positive effect on soil fertility and soil structure improvement. When the soil temperature is suitable, the humidity is appropriate, and the ventilation is good, many aerobic microorganisms in the soil proliferate and move, which promote the decomposition of humus in the soil and release a large amount of nutrients for the ground plants to absorb and use.Other fungi such as soil can Decomposition of lignin, cellulose and pectin plays a positive role in the natural circulation of other substances in the soil [6].

Humus in soil plays an important role in the normal growth of vegetation on the surface. Humus is a dark brown colloid. It is usually combined with other mineral particles in the soil. It is the main component of soil organic matter. It can improve soil fertility [7] [8].

The increase of soil temperature causes the soil microbial metabolic rate to increase and requires more oxygen, causing some microorganisms to be hindered or killed under the action of thermal potency.

The function of other biological enzymes will be affected, causing problems in metabolism, leading to regional ecology and the destruction of balance.

\subsubsection{Soil organic carbon test results}

The effect of reservoir temperature change on soil organic carbon in Zhengzhou A area is shown in Figure 4.

It can be seen from Figure 4:

(1) The organic carbon content increases fastest between $30{ }^{\circ} \mathrm{C}$ and $40{ }^{\circ} \mathrm{C}$.

(2) When the temperature reaching $40{ }^{\circ} \mathrm{C}$, excep for No.4, the organic carbon content reaches the maximum value.

(3) Then with the continuous increasing of temperature, the organic carbon content increases slowly or decreases.

(4) The closer to the reservoir or the water well, the more obvious the change is in organic carbon content.

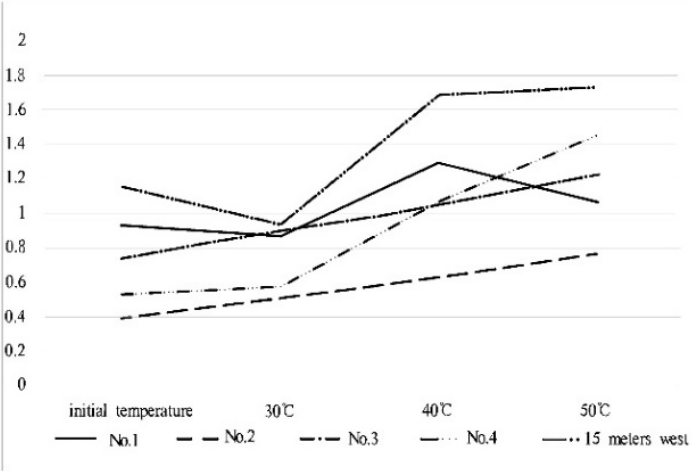

Fig4. Trend of organic carbon content in soil with temperature of the reservoir in Zhengzhou A area

It can be seen from Figure 4:

(4) The organic carbon content increases fastest between $30{ }^{\circ} \mathrm{C}$ and $40{ }^{\circ} \mathrm{C}$.

(5) When the temperature reaching $40{ }^{\circ} \mathrm{C}$, excep for No.4, the organic carbon content reaches the maximum value.

(6) Then with the continuous increasing of temperature, the organic carbon content increases slowly or decreases.

(4) The closer to the reservoir or the water well, the more obvious the change is in organic carbon content.

\subsubsection{Soil total phosphorus test results}

The effect of reservoir temperature change on soil total phosphorus in Zhengzhou A area is shown in Figure 5.

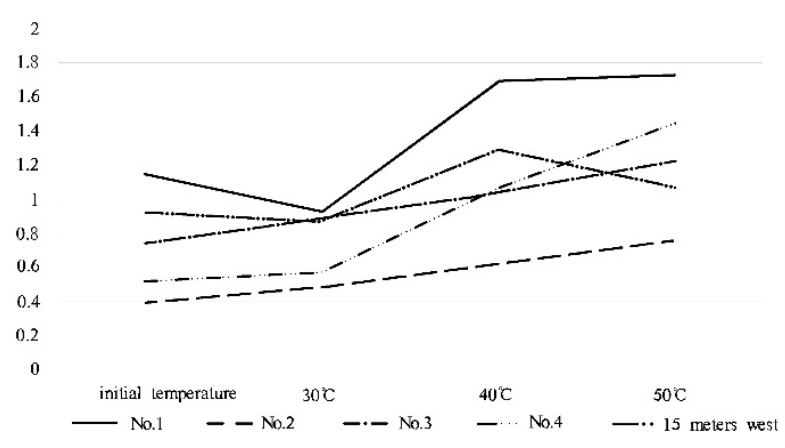

Fig5. Trend of total phosphorus content in soil with temperature in Zhengzhou A area.

It can be seen from Figure 5:

(1) The total phosphorus content is on a downward trend between $30{ }^{\circ} \mathrm{C}$ and $40{ }^{\circ} \mathrm{C}$.

(2) When the temperature reaching $40{ }^{\circ} \mathrm{C}$, excep for No.3, the total phosphorus content is keeping increasing slowly.

(3) with the continuous increasing of temperature, the total phosphorus content decreases slowly or keeps increasing.

\section{Conclusion}

From the above analysis, the following conclusions can be drawn: 
(1) With the continuous development of geothermal resources in Zhengzhou A area, the total amount of microorganisms, organic carbon and total phosphorus in the soil all changed with the increase of temperature.

(2) The number of microorganisms growed faster with the increase of temperature and reached the highest value up to $40{ }^{\circ} \mathrm{C}$.As the temperature continuing to rise ,the number of microbes growed slowly or on a downward trend.

(3) The organic carbon content increases fastest between $30^{\circ} \mathrm{C}$ and $40{ }^{\circ} \mathrm{C}$. When the temperature reaching $40{ }^{\circ} \mathrm{C}$, the organic carbon content reaches the maximum value. Then, with the continuous increase of temperature, the organic carbon content increases slowly or decrease. The closer to the reservoir or the water well, the more obvious the change is in organic carbon content.

(4) The total phosphorus content is on a downward trend between $30{ }^{\circ} \mathrm{C}$ and $40{ }^{\circ} \mathrm{C}$. When the temperature reaching $40{ }^{\circ} \mathrm{C}$, with the continuous increasing of temperature, the total phosphorus content decreases slowly or increases.

Therefore, in order to avoid the influence of temperature changes on the soil structure, it is recommended to put insulation materials around the wellhead and the reservoir to prevent the lowest loss temperature from exceeding $30^{\circ} \mathrm{C}$.

\section{Acknowledgments}

Henan Province geological research project "Study on Thermal imbalance of Shallow Geothermal Energy Development in Typical Areas of Henan Province " (Yu Guo Tu Zi Letter [2017] No.237) and "Research on Exploration and Evaluation Technology of Concealed Hot Dry Rock Resources in Henan Province" (Yu Zi Ran Zi Letter [2020] No.542).

\section{References}

1. Ge, Y., Zhang, J.1., Xi, X.H.(2017) Distribution map of geothermal resources in Henan Province [D]: No.2. Institute of Geo-Environment Survey of Henan, Zhengzhou.

2. Ge, Y.(2015) Analysis of groundwater aquifer irrigation experiment in Anyang City[J].Water Resources Protection ., 31(3):94-97.

3. Wang, X.G., Wang, H.P., Ge, Y.(2012) Research on Groundwater Resources Protection [M]. Zhengzhou: Yellow River Water Conservancy Press.

4. Wang, X.G., Ge, Y. Zhou, Q.M. (2012) Simulation analysis of hydrothermal changes during operation of groundwater source heat pump $[\mathrm{J}]$. Hydropower and Energy Science., 30(2): 139-141.

5. R.L.D.Cane,S.B.Clemes,A.Morrison.Operating Experiences with Commercial Ground-Source Heat Pumps-Part1. ASHRAE Transactions. 1996, 102(1): 911-916.

6. P.J.Lienau,T.L.Boyd,R.L.Rogers.Ground-Source Heat Pump Case Studies and Utility Programs.
Prepared For:US Department of Energy Geothermal Division. 1995: 1-5.

7. [31]D.Cane,A.Morrison,C.J.Ireland.Operating Experiences with Commercial Ground-Source Heat Pumps-Part2. ASHRAE Transactions. 1998, 104 (2A): 677-686.

8. Berry J, Bjorkman O . Photosynthetic response and adaptation to temperature in higher plants[J].Annual Review of Plant Physiology and Plant Molecular Biology,1980,31(1):491-543. 